\title{
Resgate in vitro de embriões em genótipos diplóides de bananeira ${ }^{(1)}$
}

\author{
Tárcia dos Santos $\operatorname{Neves}^{(2)}$, Sebastião de Oliveira e Silva(2) e Roberto Pedroso de Oliveira(2)
}

\begin{abstract}
Resumo - Este trabalho teve por objetivo avaliar a técnica de resgate de embriões de sementes de bananeira em genótipos diplóides e a influência de defeitos do embrião e do endosperma na germinação in vitro. Foram utilizados os genótipos Calcutta, Malaccensis, Butuhan, França, 0304-02, 1304-06, 4252-04 e 9379-09. De cada genótipo, 100 sementes recém-coletadas foram embebidas em água destilada, por 24 horas, e desinfestadas em solução à base de nitrato de prata e cloreto de sódio. Os embriões extraídos foram introduzidos em meio MS com $30 \mathrm{~g} \mathrm{~L}^{-1}$ de sacarose e $7 \mathrm{~g} \mathrm{~L}^{-1}$ de ágar, e cultivados em câmara de crescimento, no escuro e em temperatura de $26 \pm 2^{\circ} \mathrm{C}$. A germinação concentrou-se do quinto ao vigésimo dia de cultivo e apresentou uma média de 53,25\% após 45 dias, independentemente do genótipo. As espécies selvagens apresentaram porcentagem média de germinação maior do que a dos genótipos híbridos. A presença de embrião e endosperma normais não foi essencial para a germinação in vitro.
\end{abstract}

Termos para indexação: Musa, banana, cultura in vitro, germinação, híbridos.

\section{In vitro recovery of diploid embryos in banana}

\begin{abstract}
This study aimed to evaluate the recovery technique applied to zygotic embryos of banana diploid genotypes and to examine the effect of defective embryo and endosperm on in vitro germination. Genotypes Calcutta, Butuhan, Malaccensis, França, 0304-02, 1304-06, $4252-04$ and 9379-09 were used. One hundred seeds of each genotype were collected and soaked in distilled water for 24 hours. They were then disinfected by solutions of $0.5 \%$ silver nitrate followed by $5 \%$ sodium chloride. Excised embryos were put in MS medium with $30 \mathrm{~g} \mathrm{~L}^{-1}$ sucrose and $7 \mathrm{~g} \mathrm{~L}^{-1}$ agar and cultured in growth chambers under dark and $26 \pm 2^{\circ} \mathrm{C}$. Germination occurred between the $5^{\text {th }}$ and the $20^{\text {th }}$ day of growth, being $53.25 \%$ in average after 45 days independently of the genotype. Wild species showed a higher germination frequency as compared to that of the hybrid genotypes, and normal embryos and endosperm were not essential for the in vitro germination.
\end{abstract}

Index terms: Musa, banana, in vitro culture, germination, hybrids.

\section{Introdução}

A técnica de hibridação controlada tem sido utilizada no melhoramento da bananeira, e foram obtidas sementes dos cruzamentos entre diplóides (AA), e destes com cultivares comerciais dos tipos Prata e Maçã (AAB), gerando, respectivamente, híbridos diplóides (AA) e tetraplóides (AAAB). No entanto,

(1) Aceito para publicação em 27 de abril de 2000.

Extraído da dissertação de mestrado apresentada pelo primeiro autor à Universidade Federal da Bahia (UFBA), Cruz das Almas, BA.

${ }^{(2)}$ Embrapa-Centro Nacional de Pesquisa de Mandioca e Fruticultura, Caixa Postal 007, CEP 44380-000 Cruz das Almas, BA. E-mail: ssilva@cnpmf.embrapa.br a baixa porcentagem e desuniformidade de germinação, principalmente nos cruzamentos em que são produzidas sementes em pequeno número, constituem um dos fatores limitantes à obtenção de materiais híbridos (Shepherd, 1960; Stotzky et al., 1962; Shepherd et al., 1986; Shepherd et al.,1994; Silva et al., 1997).

Segundo McGahan (1961), a impermeabilidade à água e ao oxigênio provocada pela espessa cutícula das sementes em vários genótipos e a idade e qualidade das sementes são as principais causas da baixa porcentagem de germinação. No entanto, com o uso da cultura de embriões, muitas barreiras botânicas e genéticas à germinação podem ser superadas. Esta técnica pode ser utilizada para a recuperação de híbridos de cruzamentos com certo grau de incompa- 
tibilidade, micropropagação clonal, superação de dormência e estudos de fisiologia das sementes (Hu \& Ferreira, 1990).

A cultura in vitro de embriões tem sido utilizada com sucesso em inúmeros gêneros de plantas. Em bananeira, por exemplo, este tipo de cultura permite a obtenção de taxas de germinação superiores a 50\%, enquanto a porcentagem média de germinação em viveiro tem sido de 1\% (Cox et al., 1960; Vuylsteke \& Swennen, 1991). Shepherd et al. (1986) acrescentam, ainda, que a cultura in vitro permite avaliar a qualidade do embrião e do endosperma, e possibilita analisar a viabilidade das sementes, de forma a esclarecer as causas do baixo poder germinativo da semeadura direta em viveiros.

O presente trabalho teve por objetivo avaliar a técnica de resgate de embriões de sementes de bananeira em diferentes genótipos diplóides, e estudar a influência de defeitos do embrião e do endosperma na germinação in vitro, de modo a melhorar a eficiência na obtenção de híbridos.

\section{Material e Métodos}

Foram utilizadas sementes de oito genótipos diplóides de bananeira, coletadas no Banco de Germoplasma da Embrapa-Centro Nacional de Pesquisa de Mandioca e Fruticultura, sendo duas espécies selvagens de Musa acuminata-AA (Calcutta e Malaccensis), duas selvagens de M. balbisiana-BB (Butuhan e França) e quatro híbridos de M. acuminata-AA 0304-02 (Calcutta x Madang), 1304-06 (Malaccensis x Madang), 4252-04 [M53 (híbrido da Jamaica) x Kumburgh] e 9379-09 [1741-01 (Jari Buaya x 0304-02) x 2803-01 (Tuu Gia x Calcutta)].

As sementes resultantes de polinização aberta foram retiradas de frutos maduros, de pelo menos 12 plantas, lavadas em água corrente, despolpadas e embebidas em água destilada por 24 horas.

As sementes foram desinfetadas por meio de assepsia em câmara de fluxo laminar, utilizando nitrato de prata a $0,5 \%$, por 10 minutos e, em seguida, cloreto de sódio a $5 \%$, por 5 minutos. Após esse tratamento, foram realizadas três lavagens em água destilada esterilizada.

A extração dos embriões foi realizada em câmara de fluxo laminar, sob estereoscópio, sobre papel de filtro estéril, usando-se pinça e bisturi. As sementes foram classificadas quanto ao endosperma em normal (semente cheia), e reduzido; e quanto ao embrião, em normal (ápice e base desenvolvidos), pequeno (presença de ápices e bases, mas medindo menos de $70 \%$ do normal) e anormal (deformações no ápice e/ou base e aspecto amolecido). Foram extraídos embriões de 100 sementes de cada genótipo; cinco embriões foram colocados com o ápice voltado para cima, em placa de Petri $(25 \mathrm{~mm} \times 100 \mathrm{~mm})$ contendo $10 \mathrm{~mL}$ de meio de cultura MS (Murashige \& Skoog, 1962) suplementado com $30 \mathrm{~g} \mathrm{~L}^{-1}$ de sacarose e $7 \mathrm{~g} \mathrm{~L}^{-1}$ de ágar para avaliar a germinação in vitro.

Os embriões foram mantidos em câmara de crescimento sob condições de escuro e à temperatura de $26 \pm 2^{\circ} \mathrm{C}$, sendo avaliada a germinação a cada cinco dias, durante 45 dias. As porcentagens médias de germinação de cada genótipo aos 45 dias foram comparadas estatisticamente pelo teste de Scott \& Knott (1974). Os embriões que não germinaram foram avaliados quanto à presença de contaminação microbiana no meio de cultura, necrose, intumescimento e ausência de desenvolvimento.

\section{Resultados e Discussão}

A velocidade e a porcentagem de germinação foram variáveis em razão do genótipo utilizado (Figura 1). A germinação dos embriões de bananeira concentrou-se do quinto ao vigésimo dia de cultivo in vitro. A germinação in vitro ocorre mais rapidamente do que em viveiro, graças às condições ambientais e nutricionais mais propícias. Agarwal

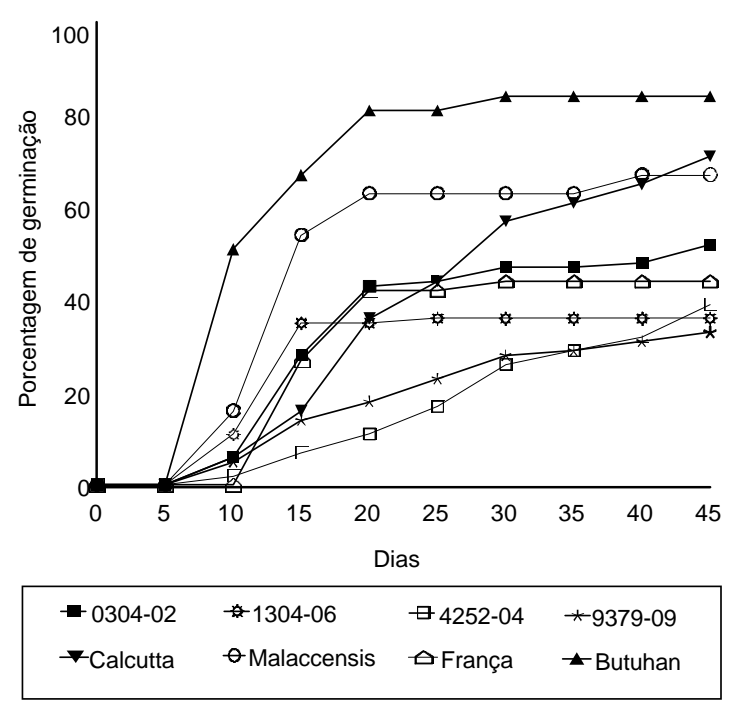

Figura 1. Porcentagem de germinação de embriões de oito genótipos de bananeira, cultivados in vitro durante 45 dias. Cruz das Almas, BA, 1998. 
(1984) obteve germinação somente a partir do décimo terceiro dia após a semeadura em uma mistura de terra esterilizada, mais areia lavada (1:1), e Stotzky et al. (1962) relataram serem necessárias de três a seis semanas para o início da germinação em solo.

A porcentagem média de germinação dos genótipos estudados após 45 dias de cultivo in vitro foi de $53,25 \%$ (Tabelas 1 e 2). Este resultado se assemelha aos reportados por Rowe \& Richardson (1975) e por Stotzky et al. (1962), que obtiveram 50\% e $52 \%$ de germinação, respectivamente. No entanto, Vuylsteke \& Swennen (1991) obtiveram de 9\% a 34\% de germinação trabalhando com diferentes genótipos e condições de cultivo in vitro; em viveiro, a porcentagem de germinação foi de $1 \%$.

Os diplóides Butuhan (BB) e 9379-09 (AA) apresentaram, respectivamente, a maior $(84 \%)$ e a menor (33\%) porcentagem de germinação (Tabela 1). A porcentagem elevada de germinação do genótipo Butuhan já havia sido relatada por Simmonds (1959), que obteve valores que variaram de $49 \%$ a $80 \%$, enquanto em Calcutta e Malaccensis esse autor verificou de $63 \%$ a $71 \%$ e de $3 \%$ a $43 \%$, respectivamente. As sementes de banana variam em tamanho e forma de acordo com a espécie e variedade. Os genótipos BB apresentaram sementes maiores que os AA, e, segundo Chin (1996), requerem diferentes condições para a germinação. As espécies selvagens de Musa acuminata (Calcutta e Malaccensis) e M. balbisiana (Butuhan e França) apresentaram maior porcentagem média de germinação $(66,50 \%)$ do que os híbridos
$(40,00 \%)$, provavelmente por serem materiais resultantes de um processo de seleção natural, que originou as bananas comestíveis, o que pode ter mantido alta a sua capacidade de germinação das sementes (Dantas et al., 1999).

A média dos embriões não germinados foi de $46,75 \%$; na maioria dos casos $(29,25 \%)$, isto ocorreu por ausência de desenvolvimento dos embriões no meio de cultura, podendo sugerir algum tipo de dormência, o que pode ocorrer mesmo em sementes maduras recém-extraídas (Chin, 1996). Parte dos embriões que não germinou apresentou intumescimento. A necrose e a contaminação microbiana ocorreram em $6,13 \%$ dos embriões (Tabela 1). Este comportamento sugere adequação do método para melhorar os processos de desinfestação das sementes, de extração dos embriões, e da composição do meio de cultura (Simmonds, 1959; Stotzky et al., 1962; Johri \& Rao, 1984; Darjo \& Bakry, 1990).

A maior parte das sementes apresentou endosperma normal (63 a 100\%), independentemente de apresentarem o genoma AA ou BB e de serem materiais silvestres ou híbridos (Tabela 2). Estes resultados indicam alta compatibilidade entre os genótipos parentais dos materiais híbridos estudados, pois, segundo Wardlaw (1965), o primeiro sinal de desenvolvimento anormal em sementes provenientes de cruzamentos "incompatíves" ocorre no endosperma.

Os genótipos Butuhan e 4252-04 apresentaram $100 \%$ de sementes com endosperma normal (Tabela 2).

Tabela 1. Comportamento in vitro de embriões provenientes de sementes com endosperma normal e reduzido de genótipos diplóides de bananeira. Cruz das Almas, BA, 1998.

\begin{tabular}{|c|c|c|c|c|c|}
\hline Genótipo & Germinados $^{(1)}$ & Contaminados & Necrosados & Intumescidos & Sem desenvolvimento \\
\hline Butuhan & $84 a$ & 0 & 1 & 1 & 14 \\
\hline Calcutta & $71 b$ & 5 & 1 & 17 & 6 \\
\hline Malaccensis & $67 b$ & 5 & 0 & 4 & 24 \\
\hline 0304-02 & $52 \mathrm{c}$ & 1 & 4 & 11 & 30 \\
\hline França & $44 c$ & 6 & 0 & 0 & 50 \\
\hline $4252-04$ & $39 \mathrm{c}$ & 3 & 10 & 14 & 34 \\
\hline $1304-06$ & $36 \mathrm{c}$ & 3 & 4 & 7 & 50 \\
\hline 9379-09 & $33 \mathrm{c}$ & 1 & 5 & 35 & 26 \\
\hline Média & 53,25 & 3,00 & 3,13 & 11,13 & 29,50 \\
\hline
\end{tabular}

(1)Médias seguidas da mesma letra não diferem entre si pelo teste de Scott-Knott (1974) a 5\% de probabilidade. 
Embora a porcentagem de germinação tenha sido a maior no diplóide Butuhan, não foi verificada a mesma correlação (endosperma normal/elevada porcentagem de germinação) nos demais genótipos, o que indica que a presença de endosperma normal não é um fator essencial para o desenvolvimento in vitro de embriões de bananeira.
A maior parte das sementes apresentou embrião normal $(61,38 \%)$, havendo $9,63 \%$ de embriões pequenos e $29 \%$ de materiais genéticos com outras anormalidades. As porcentagens médias de germinação foram de $51,73 \%, 51,92 \%$ e 56,90\% nos embriões normais, pequenos e anormais, respectivamente (Tabela 2). Esses valores, bastante próximos, suge-

Tabela 2. Comportamento in vitro de embriões provenientes de 100 sementes com endosperma normal (EN) e endosperma reduzido (ER) de genótipos diplóides de bananeira. Cruz das Almas, BA, 1998.

\begin{tabular}{|c|c|c|c|c|c|c|c|c|c|}
\hline \multirow[t]{2}{*}{ Embrião } & \multirow[t]{2}{*}{ Genótipo } & \multicolumn{2}{|c|}{ Número de sementes } & \multicolumn{2}{|c|}{ Germinação (\%) } & \multicolumn{2}{|c|}{$\begin{array}{c}\text { Contaminação e } \\
\text { necrosamento }(\%)\end{array}$} & \multicolumn{2}{|c|}{ Intumescimento (\%) } \\
\hline & & EN & ER & EN & ER & EN & ER & EN & ER \\
\hline \multirow[t]{8}{*}{ Normal } & 0304-02 & 64 & 2 & 34 & 0 & 3 & 0 & 9 & 0 \\
\hline & 1304-06 & 70 & 3 & 25 & 1 & 4 & 1 & 5 & 0 \\
\hline & $4252-04$ & 76 & 0 & 28 & 0 & 10 & 0 & 12 & 0 \\
\hline & 9379-09 & 58 & 0 & 13 & 0 & 3 & 0 & 29 & 0 \\
\hline & Calcutta & 85 & 0 & 61 & 0 & 4 & 0 & 15 & 0 \\
\hline & Malaccensis & 19 & 5 & 11 & 3 & 2 & 1 & 1 & 0 \\
\hline & França & 50 & 0 & 27 & 0 & 3 & 0 & 0 & 0 \\
\hline & Butuhan & 59 & 0 & 51 & 0 & 0 & 0 & 1 & 0 \\
\hline Média & & 60,13 & 1,25 & 31,25 & 0,5 & 3,63 & 0,25 & 9,00 & 0 \\
\hline \multirow[t]{8}{*}{ Pequeno } & 0304-02 & 2 & 0 & 1 & 0 & 0 & 0 & 0 & 0 \\
\hline & 1304-06 & 3 & 0 & 1 & 0 & 0 & 0 & 0 & 0 \\
\hline & $4252-04$ & 3 & 0 & 1 & 0 & 0 & 0 & 1 & 0 \\
\hline & 9379-09 & 0 & 0 & 0 & 0 & 0 & 0 & 0 & 0 \\
\hline & Calcutta & 5 & 1 & 3 & 0 & 0 & 1 & 1 & 0 \\
\hline & Malaccensis & 18 & 23 & 10 & 16 & 1 & 1 & 3 & 0 \\
\hline & França & 18 & 1 & 6 & 0 & 1 & 0 & 0 & 0 \\
\hline & Butuhan & 3 & 0 & 2 & 0 & 0 & 0 & 0 & 0 \\
\hline Média & & 6,50 & 3,13 & 3,00 & 2,00 & 0,25 & 0,25 & 0,63 & 0 \\
\hline \multirow[t]{8}{*}{ Anormal } & 0304-02 & 31 & 1 & 16 & 1 & 2 & 0 & 2 & 0 \\
\hline & 1304-06 & 23 & 1 & 9 & 0 & 2 & 0 & 2 & 0 \\
\hline & $4252-04$ & 21 & 0 & 10 & 0 & 3 & 0 & 1 & 0 \\
\hline & 9379-09 & 23 & 19 & 9 & 11 & 0 & 3 & 4 & 2 \\
\hline & Calcutta & 9 & 0 & 7 & 0 & 1 & 0 & 1 & 0 \\
\hline & Malaccensis & 26 & 9 & 21 & 6 & 0 & 0 & 0 & 0 \\
\hline & França & 31 & 0 & 11 & 0 & 2 & 0 & 0 & 0 \\
\hline & Butuhan & 38 & 0 & 31 & 0 & 1 & 0 & 0 & 0 \\
\hline Média & & 25,25 & 3,75 & 14,25 & 2,25 & 1,38 & 0,38 & 1,25 & 0,25 \\
\hline \multirow[t]{8}{*}{ Total } & 0304-02 & 97 & 3 & 51 & 1 & 5 & 0 & 11 & 0 \\
\hline & 1304-06 & 96 & 4 & 35 & 1 & 6 & 1 & 7 & 0 \\
\hline & 4252-04 & 100 & 0 & 39 & 0 & 13 & 0 & 14 & 0 \\
\hline & 9379-09 & 81 & 19 & 22 & 11 & 3 & 3 & 33 & 2 \\
\hline & Calcutta & 99 & 1 & 71 & 0 & 5 & 1 & 17 & 0 \\
\hline & Malaccensis & 63 & 37 & 42 & 25 & 3 & 2 & 4 & 0 \\
\hline & França & 99 & 1 & 44 & 0 & 6 & 0 & 0 & 0 \\
\hline & Butuhan & 100 & 0 & 84 & 0 & 1 & 0 & 1 & 0 \\
\hline Média & & 91,88 & 8,13 & 48,50 & 4,75 & 5,25 & 0,88 & 10,88 & 0,25 \\
\hline
\end{tabular}


rem que a eficiência da germinação in vitro ocorre mesmo em embriões pequenos ou com algumas anormalidades.

Os genótipos Malaccensis e 9379-09 foram os que apresentaram maior ocorrência de sementes com endosperma reduzido (Tabela 2). No entanto, a utilização da técnica de recuperação de embrião proporcionou redução dos efeitos dessas más formações, possibilitando a germinação em níveis comparáveis aos das sementes normais.

\section{Conclusões}

1. A germinação de embriões dos genótipos diplóides de bananeira estudados é rápida e ocorre em elevada porcentagem sob condições in vitro.

2. Os embriões das espécies selvagens apresentam maior porcentagem de germinação do que os dos genótipos híbridos.

3. A presença de embrião e endosperma normais não é fator essencial para o desenvolvimento in vitro dos embriões.

\section{Referências}

AGARWAL, P. K. Note on effect of ethyl methane sulphate on Musa balbisiana seeds. Indian Journal of Horticulture, Bangalore, v. 41, n. 1/2, p. 93-94, 1984.

CHIN, H. F. Germination and storage of banana seeds. In: NEW FRONTIERS IN RESISTANCE BREEDING FOR NEMATODE, FUSARIUM AND SIGATOKA WORKSHOP, 1995. Kuala Lumpur. Proceedings... Montpellier : International Network for the Improvement of Banana and Plantain, 1996. p. 218-227.

COX, E. A.; STOTZKY, G.; GOOS, R. D. In vitro culture of Musa balbisiana Cola embryos. Nature, London, v. 185 , p. 403-404, 1960.

DANTAS, J. L. L.; SHEPHERD, K.; SILVA, S. de O. e; SOUZA, A. da S.; ALVES, E. J.; SOARES FILHO, W.; CORDEIRO, Z. J. M. Citologia e melhoramento genético da bananeira. In: ALVES, E. J. (Ed.). A cultura da banana: aspectos técnicos, socieconômicos e agroindustriais. Brasília : Embrapa-SPI, 1999. p. 107-150.
DARJO, P.; BAKRY, F. Conservation et germination des graines de bananiers (Musa sp.). Fruits, Paris, v. 45, n. 2, p. 103-113, 1990.

HU, C. Y.; FERREIRA, A. G. Cultura de embriões. In: TORRES, A. C.; CALDAS, L. S. (Ed.). Técnicas e aplicações da cultura de tecidos de plantas. Brasília : Associação Brasileira de Cultura de Tecidos e Plantas/EmbrapaCNPH, 1990. p. 71-85.

JOHRI, B. M.; RAO, P. S. Experimental embryology. In: JOHRI, B. M. (Ed.). Embryology of angiosperms. Berlin : Springer, 1984. p. 744-802.

McGAHAN, M. W. Studies on the seed of banana. I. Anatomy of the seed and embryo of Musa balbisiana. American Journal of Botany, Columbus, v. 48, n. 3, p. 230-238, 1961.

MURASHIGE, T.; SKOOG, F. A revised medium for rapid growth and bioassays with tobacco tissue cultures. Physiologia Plantarum, Copenhagen, v. 15, p. 473-497, 1962.

ROWE, P.; RICHARDSON, L. Breeding banana for disease resistance, fruit quality and yield. La Lima : Tropical Agriculture Research Service Information, 1975. 41 p. (Bulletin, 2).

SCOTT, A. J.; KNOTT, M. A cluster analysis method for grouping means in the analysis of variance. Biometrics, Washington, v. 30, p. 507-512, 1974.

SHEPHERD, K. Seed fertility of 'Gros Michel' bananas. Tropical Agriculture, St. Augustine, v. 37, p. 211-221, 1960.

SHEPHERD, K.; DANTAS, J. L. L.; ALVES, E. J. Melhoramento genético da bananeira. Informe Agropecuário, Belo Horizonte, v. 12, p. 11-19, 1986.

SHEPHERD, K.; DANTAS, J. L. L.; SILVA, S. O. Breeding of Prata and Maçã cultivars for Brazil. In: INTERNATIONAL NETWORK FOR THE IMPROVEMENT OF BANANA AND PLANTAIN (Montpellier, França). The improvement and testing of Musa: a global partnership. Montpellier, 1994. p. 157-168.

SILVA, S. de O. e; MATOS, A. P.; ALVES, E. J.; SHEPHERD, K. Breeding 'Prata' (Pomme) and 'Maça' (Silk) banana types current achievements and opportunities. Infomusa, Montpellier, v. 6, n. 2, p. 7-10, 1997. 
SIMMONDS, N. W. Experiments on the germination of banana seeds. Tropical Agriculture, St. Augustine, v. 36, n. 4, p. 259-273, 1959.

STOTZKY, G.; COX, E. A.; GOOS, R. D. Seed germination studies in Musa. I. Scarification and aseptic germination of Musa balbisiana. American Journal of Botany, Columbus, v. 49, n. 5, p. 512-520, 1962.
VUYLSTEKE, D.; SWENNEN, R. Biotechnological approaches to plantain and banana improvement at IITA. In:- Cell and tissue culture. Ibadan : International Institute of Tropical Agriculture, 1991. p. 143-149.

WARDLAW, C. N. Physiology of embryonic development in chromophytes. In: RUHLAND, N. (Ed.). Encyclopedia of plant physiology. Berlin : Springer, 1965. v. 15, p. 844-965. 